\title{
The Adjustment Of Spatial Price Indexes For Geographical Differences In Standards Of Consumption: An Application Of The Hedonic Method
}

\author{
Don Bellante and Ruth Ann Killion*
}

It has long been recognized that over time the characteristics of items that are included in price indexes change. For example, autos get larger and include more and different types of standard equipment. As a consequence, a price index may exaggerate the extent to which inflation has occurred since these quality changes may add to the prices of the indexed items. ${ }^{1}$ When this happens, price and quality changes are measured, whereas only price changes are desired. Fortunately, on a year to year basis, few items will be much affected by such quality changes.

The problem of qualitative change over time has its analog in placeto-place comparisons of living costs, such as the City Worker Family Budgets. $^{2}$ The City Worker Family Budgets are not, strictly speaking, price indexes. The same "market basket" of goods is not priced in each city, in recognition of the fact that different bundles of goods are necessary in different places in order to maintain the same level of living. The Family Budgets have, however, been used in a number of studies as a measure of geographical differences in living costs. ${ }^{3}$ Regional incomes differ, however, and these income differences will result not only in differences in the quantities of goods purchased, but also in the qualitative characteristics of these goods. Use of the Family Budgets, then, will exaggerate geographical differences in living costs, most specifically housing costs, since higher incomes will induce the purchase or rental of housing with more expensive characteristics. It would be inappropriate to allow differences in standards of housing consumption to be reflected in a geographical price or cost of living index, just as it would be inappropriate to price different types of automobiles in different places. While pricing exactly the same type of auto in each place is relatively easy, pricing the same type of housing proves difficult.

The State of Florida has been confronted by this difficulty, and its experience serves as a good illustration of the problem. In the fall of each year since 1972, the State of Florida has compiled a price index for

\footnotetext{
*Don Bellante and Ruth Ann Killion are, respectively, Associate Professor of Economics at Auburn University, and Statistician, Statistical Methods Division, Bureau of the Census. The respective authors were formerly Assistant Project Director and Statistician for the Florida Cost of Living Project. The partial support of the Auburn University Grant-in-Aid program is gratefully acknowledged.
} 
each of its 67 counties, called the Florida Price Level Index. The index is patterned after the Consumer Price Index, except that it compares prices in each county to the state-wide avera.ge at a specific point in time rather than comparing prices over time at a specific location. Thus a 1974 index value of 108.5 for Monroe County, for example, implies that consumer prices in that county were an average of $8.5 \%$ higher than the average price level for the state that year. Florida is at present the only state that constructs such an index, although a number of states are currently considering the construction of similar spatial indexes.

In the first year of the index, it became apparent that it is virtually impossible to price a sufficiently large number of reasonably similar apartments in each county throughout the state. Locating and pricing similar owner-occupied housing proved to be even more difficult. As a consequence, the State adopted what is called the "hedonic" or characteristics method for the apartment rent and owner occupied housing components of its index. Although the hedonic method was developed and has been applied in studies of price comparisons for specific items, ${ }^{5}$ Florida became the first governmental body to use this method in an ongoing, comprehensive price index.

The hedonic method involves the use of regression analysis. Rather than attempt to price similar apartments and houses, the Florida Department of Administration (the author of the index) collects prices and rents from a random sample of all apartments and recently sold one-family houses in each county. In addition to prices and rents, information is obtained on each unit's characteristics: for houses, some of these characteristics are the number of square feet, number of stories, number of bathrooms, whether it is centrally air conditioned, the type of exterior, and the price and size of the lot; for apartments, information is gathered on the number of rooms, number of bathrooms, whether electricity, air conditioning, other appliances, utilities, or other extras (such as a swimming pool) are provided, whether the apartment has its own kitchen, and the year the apartment was built. ${ }^{6}$

Next the effect of these characteristics on the price or rent of the unit is determined through regression analysis. For apartments, the procedure is as follows: The actual (unadjusted) monthly rents obtained for each apartment are regressed on a series of variables representing the characteristics of the apartments. Additional "control" variables are included in the regression equation. These variables in the 1974 study were county median income, population, and O.B.E.R.S. region. The region variable refers to location of the county in one of the six economic regions of the state established by the Office of Business and Economic Research. The control variables are not of interest in themselves, but their inclusion in the regression equation is necessary in order to generate "reasonable" estimates of the effect of each characteristic on actual rent. For example, it would not be reasonable for air conditioning to have a coefficient of $\$ 100$ per month. Were this coefficient to occur, air 
conditioning would be serving as a surrogate for other quality differences. The purpose in using the control variables is to control for these quality differences prior to estimating the coefficients for the characteristics. The regression coefficient for each variable estimates the dollar amount by which actual rent is raised or lowered due to the presence of that characteristic. A similar technique is followed in order to estimate the effects of an owner-occupied house's characteristics on its price, except that the price of the house is adjusted for the cost of its lot.

A "standard" house and apartment are now defined (See Table I). The rent or price of each surveyed unit is adjusted upward or downward to make it conform to the standard apartment or house on the basis of observed characteristics. The adjustments used in 1974 are shown in Table II. For example, the rent of an apartment with two baths would be adjusted downward by $\$ 50.78$, since the standard apartment contains one bath.

The use of adjusted rent and the adjusted house price greatly affects the range of values observed. For example, county average rents were computed for 1973 on both an adjusted and unadjusted basis. Unadjusted county averages (with the sample limited to 3 room apartments) ranged from $\$ 89$ to $\$ 218$, with the middle 50\% ranging from $\$ 141$ to $\$ 183$.

\section{TABLE I}

Specifications for a Standard House and Standard Apartment

Standard House

1500 sq. feet

1 story

$1 \frac{1}{2}$ or more bathrooms

air conditioned

block exterior

\author{
Standard Apartment \\ 3 rooms \\ own kitchen \\ no other appliances \\ no electricity \\ no other utilities (cable, gas) \\ air conditioned \\ 1 bathroom \\ built since 1964 \\ no extras (pool, clubhouse, etc.)
}

\section{TABLE II}

Adjustments to Actual Rent or Price

Price of House

\pm 20.47 per sq. foot

-4622.70 if more than 1 story

+1446.64 if less than $1 \frac{1}{2}$ baths

+3345.22 if not air conditioned

-1354.00 if exterior not block
Apartment Rent

\pm 13.49 per room

+33.04 if doesn't have own kitchen

-28.86 if has other appliances

-30.37 if electricity paid

-10.65 if other utilities paid

+44.68 if not air conditioned

-50.78 if more than one bathroom

+12.15 if built before 1964

-27.11 if extras present 
For adjusted rents, the range was from $\$ 132$ to $\$ 208$, the middle $50 \%$ ranging from $\$ 150$ to $\$ 170$. Thus, the very substantial variation in county average apartments rents can be seen to result not only from differences in basis rental prices of apartments but also from the substantial variations in standards of housing consumption across the state. Although owner-occupied housing has not been similarly analyzed, there is every reason to expect that the effect of variations in housing standards is greater for owner-occupied housing than for apartment rents.

The affect of variations in housing standards on the overall price index is more significant than may be apparent. While rents and owner occupied housing make up only $18.35 \%$ of the total item weights in the index for Florida, the housing category accounts for over $60 \%$ of the variation in the index, after controlling for the remaining categories of the index. On the basis of the 1973 findings, it appears that the coefficient of variation for the 1974 overall index would have been about $5.8 \%$ higher had the housing figures not been adjusted by the hedonic method.

The differences in housing standards are highly correlated with geographical differences in per capita income. When the difference between unadjusted and adjusted rent for each county is regressed on that county's per capita income, the following equation is obtained (with t-ratios in parentheses):

$$
\begin{array}{ccc}
\text { Unadj. Rent }- \text { Adj. Rent }= & -40.25+.021 \text { Per Capita Annual Income } \\
-(2.21) & (3.85) \quad \mathrm{R}^{2}=.47
\end{array}
$$

Unadjusted minus adjusted rent can be interpreted as a measure of a county's average standard of rental housing: County differences in per capita income accounts for almost half of the variance in the standards of rental housing.

The Florida experience and the arguments above have implications for studies which use the City Worker Family Budgets as a spatial cost of living index. Examination of the budgets reveals that, as with the Florida Price Level Index, housing is the most important source of variation in the total budget. It is therefore highly likely that the variations in the observed cost of living in various cities are largely attributable to geographical differences in standards of housing, rather than being solely attributable to differences in the basic pricess of housing. In fact, Robert Gillingham has found that when the heclonic method is applied to rental housing meeting the specifications of the City Worker Family Budget, the adjusted rental values exhibit substantially less variation than the rent component actually used in the City Worker Family Budgets. $^{7}$ The differences in housing standards, in turn may be closely associated with regional differences in real income. Certainly, this view receives some support from the finding of Alonso and Fajans that there exists a strong correlation between per capita income and the City Worker Family Budgets. They attribute the correlation to the affect 
of income on standards of consumption. ${ }^{8}$ The studies that have used the Family Budgets as a cost-of-living index are thus liable to arrive at erroneous conclusions. For instance, Coelho and Ghali have used these Budgets to deflate regional wage data, and have concluded that, because the cost of living is lower in the South, there is actually no difference in real wages between the North and the South. ${ }^{9}$ If the differences in the Family Budget costs are partially attributable to a real income difference between North and South, however, their methodology and conclusion are subject to serious question.

The experience with the Florida Price Level Index further suggests that those states now beginning or contemplating the adoption of a spatial price index ought to incorporate the hedonic method of quality adjustments into their procedures. This is particularly true of states that experience substantial variations in per capita income within their borders.

\section{FOOTNOTES}

ITriplett, J. E., "Determining the Effects of Quality Change on the C.P.I." Monthly Wage Review, Vol. 94, (May 1971), pp. 27-32. In the case of Automobiles, B.L.S. has attempted to correct the CPI for quality changes, on the basis of cost information provided by the automobile industry.

2See U.S. Bureau of Labor Statistics. Three Standards of Living for an Urban Family of Four Persons, Spring 1967. Bulletin No. 1570-5 and subsequent revisions.

3 For example, Rasmussen, D. W. and C. J. Haworth. "Determinants of Metropolitan Cost of Living Variations," Southern Economic Journal, Vol. 40 (October 1973), pp. 183-192.

4 Florida Price Level Index, September 1974. State of Florida, Department of Administration, Tallahassee, Fla., March, 1975.

5 For examples, see Triplett, J. E. "Automobiles and Hedonic Quality Measurement," Journal of Political Economy, Vol. 77, (May/
June 1969), pp. 408-17, also Gillingham, R. and D. C. Lund. "A Hedonic Approach to Rent Determination," Proceedings, Business and Economic Statistics Section, American Statistical Association, (December 1970), pp. 184-92. IInformation on other characteristics is collected; however the characteristics listed above are the ones that have proved to be significant. TGillingham, R. "Place to Place Rent Comparisons Using Hedonic Quality Adjustment Techniques," B.L.S. Staff Paper No. 8, U.S. Department of Labor, Bureau of Labor Statistics, Washington, D.C., 1975.

8 Alonso, W. and M. Fajans, "Cost of Living and Income by Urban Size," Working Paper No. 128, Department of City and Regional Planning, University of California, Berkeley, July 1970.

${ }_{9}$ Coelho, P. and M. Ghali. "The End of the North-South Differential," American Economic Review, Vol. 61, (December 1971), pp. 932-937. 